EMERITA, Revista de Lingüística y Filología Clásica (EM)

LXXVI 1, enero-junio de 2008

pp. $67-85$

ISSN 0013-6662

\title{
UN CASO ESPECÍFICO DE TEOLEPSIA: LA PANOLEPSIA
}

\author{
M. ${ }^{\mathrm{a}}$ Cruz Cardete del Olmo \\ Universidad Complutense de Madrid
}

A SPECIFIC CASE OF THEOLEPSY: THE PANOLEPSY

\begin{abstract}
La teolepsia es un fenómeno muy extendido en la vida de los griegos antiguos, dominados por la creencia en la frecuente intervención (positiva o negativa) de los dioses en sus vidas. Pan es un dios comúnmente asociado a la posesión divina a través de dos formas: la panolepsia (posesión del ser humano por parte del dios) y el pánico (temor desmedido que el dios inflige, generalmente a soldados durante la batalla). Aunque la raíz de ambas actuaciones de Pan es similar existen diferencias importantes que son analizadas aquí.
\end{abstract}

Palabras clave: Panolepsia; pánico; dios Pan.
The theolepsy is a very extended phenomenon in Greek Antiquity because the Ancient Greeks believed that the gods intervened frequently in their lives, positively or negatively. Pan is a god commonly associated to divine possession in two ways: the panolepsy (divine possession of a human) and the panic (great horror inflicted on soldiers during a battle). Though the origin of both phenomena is similar, there are some important differences that I analyse in this article.

Keywords: Panolepsy; panic; god Pan.

La teolepsia es un fenómeno común en las religiones antiguas y, concretamente, en la griega. La presencia constante de los dioses en la vida terrenal se expresaba con cierta frecuencia a través de la posesión del fiel por parte de la deidad, posesión que ayudaba a explicar comportamientos que se salían de la norma (es famoso el caso de los epilépticos) pero, también, a fomentar la sensación de que los dioses formaban parte inexcusable del discurrir humano.

En principio, cualquier dios puede poseer a un ser humano y condicionar su comportamiento. Dependiendo de los síntomas de la posesión, la mentalidad popular la atribuía a la acción determinada de una deidad que 
se relacionaba en sus atributos, mitología o epíteto con el comportamiento desmedido que presentaba el poseído. Hipócrates, en su tratado sobre las llamadas "enfermedades divinas" (principalmente la epilepsia y cualquier otra que tuviera como síntomas convulsiones y mareos aparatosos $)^{1}$, considera que la posesión no es sino la forma en la que el pueblo supersticioso cataloga a aquellos enfermos cuyo comportamiento resulta inexplicable por cauces normales, atribuyendo a dioses determinados las distintas anomalías, como si de advocaciones se tratara. Por ejemplo, aquel que grita de modo fuerte y agudo, como un caballo, se considera poseído por Poseidón, el dios de los equinos, en un razonamiento harto simple que indigna al médico por lo extendido y ferviente de su creencia. Para la mentalidad racionalista del científico los dioses no se entrometen en la vida de los humanos, pero para el común de los griegos la presencia divina en las cosas humanas más cotidianas era una realidad palpable y demostrable a través de sus efectos.

La teolepsia no es atributo exclusivo de ningún dios específico pero, aunque cualquier deidad puede decidir poseer a sus fieles o a descreídos que les han negado, generalmente dichas posesiones se atribuyen a dioses muy poderosos (Apolo, Poseidón...) o a deidades de "los límites" como Pan, Hécate, Dioniso, Ártemis y la Madre de los Dioses. Concretamente la figura de Pan, objeto de este breve estudio, es frecuente protagonista de actos de posesión que pueden diferenciarse en dos tipos: la panolepsia propiamente dicha y el pánico. Aunque con cierta frecuencia se confunden, creo que hay diferencias básicas entre la panolepsia y los ataques de pánico. La primera se manifiesta siempre de forma individual, pues supone la posesión directa del sujeto por parte del dios. Los segundos no se abaten sobre un individuo aislado, sino sobre colectivos (generalmente colectivos militares) y en ningún momento se produce conexión entre el dios y los afectados por su intervención. El panolepto se comporta como un poseído (como un loco divino), los colectivos atacados por el pánico sólo tienen miedo.

\section{La panolepsia}

La panolepsia puede definirse como la posesión de un ser humano por parte del dios Pan y se caracteriza por repentinos accesos de locura, de furor inexplicable. El hombre pierde el contacto consigo mismo pues es el dios

${ }^{1}$ Hp., Morb. Sacr. 4. 
quien lo dirige. No se trata de una comunión, pues ésta precisa de una comunicación entre dos entidades, mientras que en el caso que ahora tratamos sólo existe una: la voluntad del dios. Aquellos que la sufren y quienes la presencian se asustan ante la intensidad de la posesión, sean sus efectos maléficos o benéficos. La confluencia entre el plano divino y el humano mueve, sobre cualquier otra sensación, al temor. El hombre ha perdido su capacidad de interacción fluida con las deidades, ha perdido la relación que mantuvo in illo tempore, antes de que ambas esferas, la humana y la divina, se separaran y el hombre se viera por completo sometido a la voluntad, cuando no al capricho, de los dioses. Por tanto, la aparición de la deidad en su vida le turba y preocupa.

Además, Pan es un dios especialmente turbador, pues su naturaleza combina continuamente los contrarios: lo humano y lo animal, la paz y la ferocidad, la dulzura amorosa y la lujuria desenfrenada, la sensibilidad artística y la obscenidad, la capacidad creativa y la destrucción. Sin adentrarme profundamente en el estudio de esta deidad, pues tal análisis desbordaría el marco de este artículo, sí creo necesarias algunas puntualizaciones sobre el carácter carismático de la misma.

Más que Hermes, más que Poseidón Hipio, más que Ártemis o que cualquier otra deidad, Pan es el dios de la Arcadia y la Arcadia es la tierra de $\mathrm{Pan}^{2}$. La exageración del mito de la Arcadia, rica en ganado ${ }^{3}$, convierte a Pan, un dios pastoril, en un símbolo más de los muchos que jalonan a la mítica Arcadia $^{4}$. Su genealogía es confusa y contradictoria (pueden registrarse más de 14 versiones de su nacimiento ${ }^{5}$ ), ya que se fue fraguando a tenor de los impulsos que llevaron a Pan cada vez más lejos de su Arcadia natal y más cerca del Olimpo. Se dice de él que nació en el monte Cileno (siendo sus progenitores Hermes y la ninfa Dríope) ${ }^{6}$, en el Liceo (hijo de Zeus y Calisto, hermano gemelo de Arcas, héroe fundador arcadio) ${ }^{7}$, en Tegea (vástago de

2 Pi., Fr. 95 Snell; h.Pan. 30-32; Call., Dian. 87; AP V 139; Theoc. I 122-126; VII 115; Verg., B. IV 59; Sil.Ital. XIII 302; Prop. I 18; Porph., Antr. 20.

3 h.Pan. 30-32.

${ }^{4}$ Sobre la formación de la imagen mítica de Arcadia a lo largo del tiempo y los numerosos tópicos que sobre ella se han construido remito a un estudio anterior (M. C. Cardete 2005, pp. 11-26).

5 Remito a la cumplida genealogía que recoge J. A. Hild 1969, pp. 296-302.

${ }^{6}$ h.Pan. 31. M. Jost 1985 , p. 460, apunta la posibilidad de que esta tradición sea una invención poética.

7 Sch. Theoc. 1-4 (FGrHist 457 F 9). 
Aither y la ninfa Énoe) ${ }^{8}$ o en Mantinea (hijo de Hermes y Penélope) (M. Jost 1985, 462; Mactoux 1975, 221). Sobre lo que hay un acuerdo unánime es sobre su naturaleza caprina y su advocación pastoril. Las fuentes se complacen en el uso de adjetivos tales como bicorne o cáprido y sus funciones y actividades se relacionan principalmente con la caza menor (favorece a los pequeños cazadores, que le ofrendan sus armas ${ }^{10}$, y él mismo, mientras vagabundea por los montes ${ }^{11}$, se dedica a la caza de pequeñas piezas tales como tordos, perdices, codornices ${ }^{12}$ e incluso jabalíes ${ }^{13}$, pero no de animales más grandes) y la ganadería de ovejas y, sobre todo, de cabras. La simbiosis entre el dios, las cabras y quienes las pastorean es tan fuerte que el primero aparece alternativamente convertido en las unas o en los otros sin mediar distancia perceptible, como una imagen más de la bestialidad divinizada de $\operatorname{Pan}^{14}$, pues él mismo no es sino un macho cabrío, y de su cercanía con los pastores que, al igual que los cazadores con sus armas, le ofrendaban sus cayados y flautas pastoriles cuando se retiraban ${ }^{15}$. Es por eso que el hábitat preferido de Pan son las montañas y que el epíteto montaraz se repite incesante ${ }^{16}$. De hecho, los lugares de culto a Pan que Pausanias recoge en Arcadia son, generalmente, santuarios en montañas, generalmente agrestes, como el Ménalo ${ }^{17}$, o cami$\operatorname{nos}^{18}$, lejos de las ciudades. Pan se convierte, pues, en un elemento clave del paisaje, puesto que su figura contribuye a enlazar, en una red contextual de

\footnotetext{
${ }^{8}$ Referencia de Arieto de Tegea, escritor del s. III a. C., en un escolio al Reso de Eurípides (v. 36, FGrHist 316 F 4).

${ }^{9}$ h.Pan. 5-7; Ou., Met. XIV 515; Hdt. II 46.

${ }^{10} A P$ VI 13, 14, 177, 188; IX 337.

${ }^{11}$ Cal., Dian. 87-97; h.Pan. 12-15.

${ }^{12}$ Ver nota 10.

${ }^{13}$ AP VI 34; Leon. en POxy. 662. La cabra salvaje, característica del Peloponeso, también se encuentra bajo su patronazgo (M. Jost 1985, 469).

${ }^{14}$ A este respecto resulta más que significativo el fragmento de una cratera de volutas de figuras negras procedente del Ática, datable entre el 500-490 a. C., que se conserva en el Allard Pierson Museum de Amsterdam (n. ${ }^{\circ}$ 2117). En él puede apreciarse a Pan bajo forma caprina y con brazos humanos tocando la flauta en un contexto simposiasta, acompañado de un sátiro.

${ }^{15}$ Longus IV 26.2-3.

${ }^{16}$ Pi., Fr.156 Snell; h.Pan.; S., Ai. 697-698; Call., Dian. 97; AP VI 154, 334; IX 337; XII 128; XVI 226; Leon. en POxy. 662; Verg., B. VIII 22-26; Ou., Fast. 268-280; Sil.Ital. XIII 302; Paus. VIII passim; Nemesianus, Bucol. III 17; E., IT 1125-1131; Nonn., D. V 269 y VI 275.

${ }^{17}$ Paus. VIII $6.4 ; 24.4 ; 30.2-4$ y $6 ; 36.8 ; 37.11-12 ; 38.5$ y $11 ; 54.6-7$.

${ }^{18}$ Paus. VIII 36.7; 53.11; 54.4.
} 
significado, los aspectos económicos que dominaban la vida de ganaderos y cazadores a pequeña escala (rebaños de cabras y ovejas, ramoneo, pasto, caza menor...) con determinados espacios (cuevas, montañas, pastos, límites, fronteras...) que, al enlazarse y ensamblarse, acaban construyendo paisajes mentales y religiosos de una gran fuerza social. Pan es un eje mítico de conexión y transmisión, una transposición divina de los referentes humanos (pastores, cazadores) que conectan la comunidad con su territorio. Pan encarnaría, por tanto, el "dwelling" 19 de aquellas comunidades en las que la ganadería y la caza menor constituyen actividades básicas de supervivencia y en las que, por lo tanto, la montaña dista mucho de ser un enclave aislado, como se repite desde el tópico, sino un nodo de oposición controlada y dominada, un espacio de trasgresión domesticado, pues resulta imprescindible para el desarrollo comunitario (M. C. Cardete 2005, 169-171).

La siringa, zampoña o caramillo, cuya invención se le atribuye ${ }^{20}$, es un elemento típico de los pastores y uno de los símbolos más representativos de $\operatorname{Pan}^{21}$. Mientras que la música apolínea es precisa, aritmética, áulica y civil la de Pan es agreste, pastoril, penetrante, espontánea, inspirada (I. Cazzaniga 1978), una música estremecedora y delirante que llama al desenfreno, no a la cordura, y que sólo él puede arrancar a la siringa. Por ejemplo, el himno cultual de Pan, creado por Píndaro, ${ }^{22}$ está escrito en eólicos con una ligera mezcla de créticos, combinación no usual en Píndaro pero apropiada para el dios al que trataba de celebrar, pues los créticos contienen un punto de rapidez y estatismo que acompaña perfectamente al dios cabra (J. Haldane $1968,18-31) .{ }^{23}$ Los rebaños le siguen cuando él sopla por las cañas de la

19 "Dwelling" responde a un concepto desarrollado por Ch. Tilley 1994. Implica un contexto, una red de significado, una apropiación simbólica del entorno que coincide en parte con la apropiación física, pero que va más allá. La contextualidad de la percepción se expresa, según Tilley, en la capacidad constructora del "paseo", del "camino andado". El hombre que anda (y el pastor es un tipo de hombre que camina constantemente) se apropia de los lugares por los que pasa convirtiéndolos en hitos y nodos de un paisaje que él conforma en su mente, construyendo un conjunto ordenado de referentes culturales. El paisaje así entendido se construye a cada paso, en cada segundo, con retazos de la memoria, objetos, ideas aprendidas, esquemas impuestos (Ch. Tilley 1994, p. 31; G. Children y G. Nash 1997, p. 2; J. Chapman 1997, p. 31).

${ }^{20}$ Verg., B. II 34 y VIII 26; Hyg., Fab. 274.

${ }^{21}$ Ach.Tat.VII 5.6-8.

${ }^{22}$ Pi., Fr. 95-99 Snell.

${ }^{23}$ El culto a Pan en Beocia se impondría posiblemente a raíz de su introducción en Atenas. Una leyenda cuenta cómo Píndaro se inspiró para inscribir su Himno a Pan cuando descubrió que el dios entonaba sus peanes entre el Helicón y el Citerón (J. Haldane 1968, 21). 
zampoña ${ }^{24}$, los pastores y rústicos se paran a escucharle ${ }^{25}$, nadie puede tocar su flauta y arrancarle los bellos sonidos que él consigue porque la suya es una siringa de dioses ${ }^{26}$.

La mitología olímpica le admite en su papel de jefe del coro de las ninfas ${ }^{27}$ e incluso de los dioses ${ }^{28}$ y lo sitúa en el centro de danzas extáticas y salvajes. Ya dice Menandro que uno no se dirige a Pan en silencio ${ }^{29}$, su Himno Homérico le califica de amante del ruido ${ }^{30}$ y Píndaro lo alaba como el perfecto danzante $^{31}$. No se le celebra en silencio, sino a través del alboroto y la risa (una de las manifestaciones del panolepto es precisamente el ataque de risa indiscriminado), lo que conecta con su sexualidad bulliciosa y salvaje, así como con la naturaleza de las propias cabras, animales muy ruidosos.

De la música pastoril a la posesión sexual sólo media, en el mundo pánico, un segundo de atracción física. La sexualidad de Pan es violenta cuando se le niegan sus deseos, rápida, sorpresiva incluso, y libre, como la de los animales. No guarda relación alguna con el matrimonio, como ejemplifican sus relaciones con las ninfas, ni es un dios de los cánones ni de la pureza sino de lo salvaje, de lo caótico, y es en esos parámetros donde se mueven sus relaciones sexuales con las ninfas o con las cabras.

La asociación de Pan con Eco se debe al hecho de que la música pastoril del dios se escuchaba a lo largo y ancho de las montañas, como si el eco la repitiera $^{32}$. Mitógrafos y poetas convirtieron un hecho físico (la acústica de las montañas repitiendo los acordes de las flautas de los pastores) en una bella historia de amor trágico con Pan como protagonista, introduciendo además una mezcla de pánico (el que infiere a bestias y pastores) y violencia sexual (la sexualidad de Pan es violenta pero no tanto porque sea forzada, sino por su misma condición salvaje y directa) características del $\operatorname{dios}^{33}$.

${ }^{24}$ Sil.Ital. XIII 302.

${ }^{25}$ Lucr. IV 580-594.

${ }^{26}$ Nemesianus, Bucol. III

${ }^{27}$ h.Pan. 28-25.

${ }^{28}$ S., Ai. 698.

${ }^{29}$ Men., Dysc. 430.

${ }^{30}$ h.Pan. 37.

${ }^{31}$ Pi., Fr. 98 Snell. Sobre su pasión por el baile hablan también Ar., Au. 1098-1099; Pi., P. III 76-79; Str. X 3, 15 o Pl., L. 815e.

32 "(...) modulante joven del aire nacida de la voz amor sintió” canta Teócrito en $\mathrm{La} \mathrm{Si-}$ ringa, v. 5-6.

${ }^{33}$ Luc., DDeor. XXII 4; Orph., H. XI 9; Nonn., D. XVI 289 y XXXIX 130. 
Siringa es otro bello mito que mezcla la música (elemento imprescindible del dios, como lo es el pánico) con la violencia: Siringa era en origen una ninfa que, perseguida por Pan, rogó a los dioses que la protegieran y la tierra la convirtió en cañas que Pan cortó para construir la siringa, el instrumento que lo define ${ }^{34}$. En cuanto a Pitis, esta ninfa se convirtió en pino que es, precisamente, una de las epifanías de $\operatorname{Pan}^{35}$.

La exageración de la potencia sexual de Pan llegó a tal extremo (de hecho, se le hace padre de Iynx, la personificación del deseo violento e ilimitado, producto de los amores con $\mathrm{Eco}^{36}$ ) que se le convirtió en protagonista de todos y cada uno de los tipos de encuentros y relaciones sexuales: del onanismo a la zoofilia pasando por la homosexualidad, la pederastia y la heterosexualidad desbordada, a pesar de que se le consideró infértil en la mayoría de los casos en una más de las contradicciones que caracterizan a esta figura (P. Borgeaud 1979, 119) ${ }^{37}$.

Eurípides describe las convulsiones que agitan a Glauce, hija de Creonte, prometida de Jasón, tras probarse el vestido envenenado de Medea con un gran realismo y la criada de la princesa atribuye dichas convulsiones a la

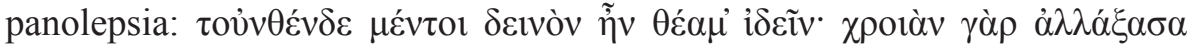

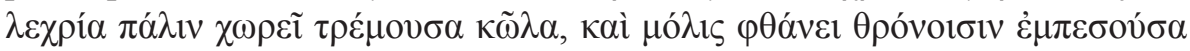

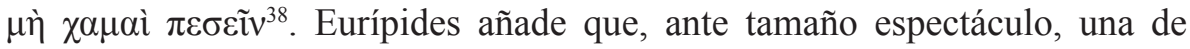
las viejas criadas de la princesa se asusta y atribuye el ataque a un acceso de furor provocado por Pan o algún otro dios. Inmediatamente la mujer se apresura a lanzar un conjuro para evitar lo que ella considera un acto divino caprichoso que castiga a su señora ${ }^{39}$. Por su parte, Jámblico explica que hay que distinguir entre panoleptos y ninfoleptos y se compromete a explicar por qué los poseídos por estos dioses saltan, se pierden por las montañas, se atan $\mathrm{y}$, finalmente, son sanados a través de los sacrificios ${ }^{40}$.

${ }^{34}$ Il. XVIII 525; Ach.Tat.VIII 5.6-9; Longus II 34, 39; Paus. VIII 38.11 y 36.8; Theoc. IV 28; Ou., Met. I 690; Hyg., Fab. 274.

${ }^{35}$ Longus I 27.2; Nonn., D. II 108, 118.

${ }^{36}$ Plin., $H N$ XI 2, 56; Theoc. II 17; Pi., P. IV 213-219; Tz., Ad Lyc. 310; Sch. Pi., N. IV

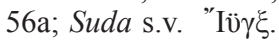

${ }^{37}$ Theoc. I 81-90.

${ }^{38}$ E., Med. 1166-1175: "Entonces tuvo lugar un espectáculo horrible de ver: cambiando el color retrocede inclinada con todos sus brazos temblorosos, y apenas si le da tiempo a reclinarse en su trono para no caer a tierra".

${ }^{39}$ E., Med. 1176-1177.

${ }^{40}$ Iambl., Myst. III 10. 
La posesión es un modo más, por parte de los dioses, de marcar la infinita distancia que les separa de los pobres humanos, con los que juegan a su antojo. Su repentina aparición en la vida humana puede conducir al caos y el desastre, pero también al regocijo y la exaltación. Es el dios quien decide qué efecto provocar en el humano. Éste sólo puede esperar benevolencia.

Así, frente a los duros testimonios que acabo de recoger, en los que la posesión se entiende como un latigazo repentino que puede llevar al hombre a cometer todo tipo de atrocidades sin ningún control de sus actos, existe el caso contrario, el dios que reporta, con su posesión, paz y regocijo. Aristó-

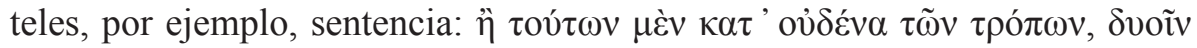

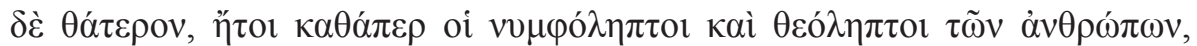

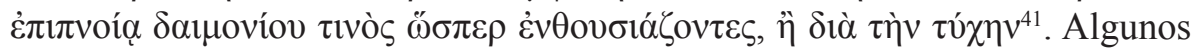
epigramas de época helenística ${ }^{42}$ recogen el mismo pensamiento con respecto a aquellos que han sido poseídos o "raptados" por las ninfas (los ninfoleptos), a los que no sólo no se les considera locos o enfermos, sino de los que incluso se piensa que han sido elegidos por los dioses para un destino mejor (W. R. Connor 1988, 155-188) ${ }^{43}$.

Algunos historiadores han comparado informes psiquiátricos y estudios médicos sobre la histeria con las descripciones que nos han llegado de la panolepsia, concluyendo que en nuestros días lo calificaríamos de "disociaciones de la personalidad" (W. R. Connor 1988, 155-189) o de "ataques epilépticos" ${ }^{44}$. Otros consideran que los fenómenos teolépticos son conse-

${ }^{41}$ Arist., EE 121422-26: "La felicidad (...) viene por uno de estos medios: por la inspiración de algún ser demoníaco, a manera de transportados, como es el caso de las personas poseídas de ninfas o dioses, o por obra de la fortuna".

${ }^{42}$ Un bello ejemplo en $A P$ VII 518: "A Astácides el cretense, cabrero, una ninfa llévose del monte y hoy es un ser sagrado. Nunca a cantar volveremos a Dafnis, pastores, bajo las dicteas encinas, mas a Astácides siempre".

${ }^{43}$ La mayoría de los ninfoleptos experimentan la posesión positivamente, ya que les confiere un don poético querido por dioses y hombres. En el mundo helenístico, no obstante, el rapto adquiere connotaciones más físicas y se ve como un peligro mortal, caso del rapto de Hilas (Theoc., XIII 40-61; A.R. I 1221-1260 - ya con un carácter más dulce pero conservando aún la motivación sexual y caprichosa-; Prop. I 20.7-52), revestido de implicaciones sexuales, de ahí que, dada la escasa presencia pública de la homosexualidad femenina en Grecia, los ninfoleptos sean siempre hombres. El ninfolepto también puede ser aquel que desarrolla una devoción religiosa muy fuerte por las ninfas, como por ejemplo Arquédamo de Tera, que construyó la famosa cueva de Vari para ellas (J. Larson 2000, pp. 13-14).

${ }^{44}$ P. Borgeaud 1988, p. 105 resalta la creencia de que la carne de cabra provocaba epilepsia.

EMERITA (EM) LXXVI 1, enero-junio 2008 pp. 67-85

ISSN 0013-6662 
cuencia del agotamiento y del cansancio físico sufrido por cazadores y pastores en el ejercicio de sus funciones que, combinadas con temperaturas elevadas o muy bajas, la soledad de los bosques, el hambre o el miedo, darían lugar a alucinaciones cuya explicación sólo concebían atribuirle a un dios. Esta es la tesis de C. Meillier (1975, 121-131), C. Gallini (1961) o E. R. Dodds $(1960,115)$, quien explica la aparición de Pan a Filípides en el Partenio ${ }^{45}$ como producto de una alucinación provocada por el cansancio y lo abrupto del terreno por el que transitaba.

No es mi intención negar que las condiciones físicas, orográficas y meteorológicas son un factor importante a la hora de encarar el análisis de reacciones psíquicas y físicas desproporcionadas como las que aquí expongo, pero creo que no podemos reducir estos fenómenos a una cuestión de "salud pública", que no podemos equiparar los fenómenos griegos de la panolepsia y del pánico con los ataques de ansiedad (lo que hoy concebimos como pánico) de la sociedad moderna. Entre otras razones porque, aún en el caso de que lo fueran, no eran entendidos como tales y, por lo tanto, su función en el contexto social (su realidad) no dependía de las causas físicas que provocan los ataques, sino de los valores religiosos que se les suponían a los mismos. Debemos, pues, buscar en las causas que llevaron a los griegos a construir una realidad en la que los dioses se comunicaban con los humanos y en ocasiones, para ello, los poseían y dominaban, no explicar dicha posesión a través de razonamientos lógicos que encajen con la importancia que nuestro mundo le otorga a las ciencias de la salud, pues en este último caso estaríamos dinamitando el contexto histórico (M. C. Cardete 2004).

Ya Hipócrates sentenciaba respecto a estos ataques que eran producto del cerebro y de la herencia familiar y no de los dioses ${ }^{46}$. No obstante, a pesar de estas conclusiones, la población común seguía creyendo que las reacciones descritas eran el resultado de la posesión o la intervención divina así que, aún admitiendo que se produjeran por causas físicas o mentales similares a las que ahora conocemos (situaciones amenazantes, malestar físico, adversas condiciones naturales, epilepsia incluso), debemos admitir que la concepción y reacción ante el fenómeno difiere por completo entre nuestro mundo y el griego antiguo, entre los intelectuales y científicos como Hipócrates y el común de los helenos. Si la mayoría de la población

${ }^{45}$ Hdt., VI 105.

${ }^{46}$ Hp., Morb. Sacr. 5-6. 
consideraba a los epilépticos como poseídos por los dioses (como así parecen demostrar las fuentes), entonces esas posesiones adquieren realidad, ya que forman parte integrante del imaginario a través del cual los griegos construyeron su mundo ${ }^{47}$.

Tanto el pánico como la panolepsia (y aquí encontramos uno de los puntos de contacto más importantes entre ambos fenómenos) tienen algo de regresión cultural, un significado que va más allá de lo puramente físico o psíquico, algo que entra en los dominios de lo simbólico. Es precisamente a través de las deidades de "los límites", como Pan, a caballo entre la civilización y la barbarie, entre lo considerado plenamente natural (bestial si se quiere) y lo humano, entre el plano de lo terreno y lo divino, como se explican los estados irracionales del hombre.

Al apropiarse de la voluntad de un ser humano, Pan traspasa la difusa línea que separa la divinidad de la humanidad, e incluso se podría decir que la rompe. El miedo encadena, embota los sentidos, como la posesión enajena, pero al tiempo liberan; el uno de las restricciones de la lógica y del deber, la otra de uno mismo, dejando al hombre en un estado tan primitivo que ni siquiera se reconoce ni se sabe humano y hasta los más elementales conceptos en los que se apoya la vida "civilizada" se esfuman para adentrarse en el reino de la confusión absoluta y, por tanto, de la total libertad sin normas.

\section{El pánico}

La panolepsia y el pánico se atribuían en la Antigüedad a un mismo dios, Pan, pero ni el mecanismo ni los efectos ni las consecuencias de la una y del otro son los mismos, como se percibe en la descripción que de ambos fenómenos nos dan los autores antiguos. Ya hemos visto cómo Pan se apodera de la voluntad de los panoleptos, ejerciendo su deseo divino a través de un cuerpo humano. Veamos ahora cómo describen algunos autores el pánico

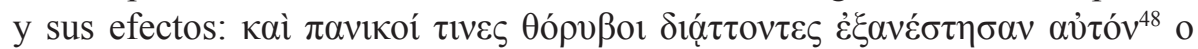

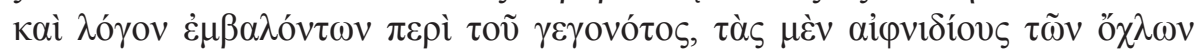

\footnotetext{
${ }^{47}$ Sobre el concepto de construcción de la realidad y la configuración de paisajes mentales remito a Cardete 2005 y a la bibliografía allí expuesta.

${ }^{48}$ Plu., Pomp. 68: "Suscitáronse en el campamento ciertos terrores pánicos que le hicieron levantar".
}

EMERITA (EM) LXXVI 1, enero-junio 2008 pp. 67-85

ISSN 0013-6662 


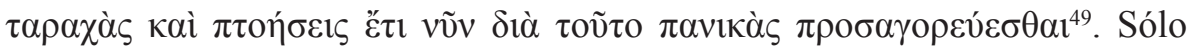
en épocas tardías el pánico y la panolepsia se entremezclan. Por ejemplo, Pausanias aventura que los miedos que no tienen una causa determinada proceden del dios $\operatorname{Pan}^{50}$ y su Himno órfico describe a Pan como propiciador de horribles temores entre los humanos ${ }^{51}$.

El pánico actúa, sobre todo, en el campo de batalla, aterrorizando a los soldados que, perdido el raciocinio, corren espantados de un lado a otro desbaratando los planes de guerra. La finalidad del dios es ayudar a un bando frente al otro y no es en absoluto arbitrario: Pan escoge al ejército al que desea beneficiar o perjudicar por cualesquiera motivos (falta de respeto hacia él, por ejemplo ${ }^{52}$ ). De todas formas, en la posesión repentina, arbitraria y catastrófica, es donde hallamos las raíces del fenómeno, posteriormente desvirtuado por la adecuación a un mundo, el militar, en principio extraño. Entre la panolepsia y el pánico hay, pues, puntos de contacto innegables: la multitud despavorida es al pánico lo que el individuo poseído es a la panolepsia.

El pánico es una adaptación del fenómeno panoléptico al ambiente militar. Si la panolepsia no es más que una manifestación concreta del fenómeno general de la teolepsia, podemos preguntarnos por qué Pan fue elegido artífice del pánico y no cualquier otro dios de los que habitualmente poseen a sus fieles. Algunos consideran que Pan fue un dios guerrero o con atribuciones bélicas desde muy pronto (M. Jost 1985, p. 473) pero no hay ninguna fuente que hable de esa supuesta conexión hasta el s. V a. C.; es más, las fuentes que remiten al pánico son tardías, pero las que lo relacionan con Pan más aún (la mayoría se concentran entre el s. II-V d. C.). ${ }^{53}$ También se ha propuesto que fue a partir de Eneas el Táctico cuando el pánico militar se empezó a atribuir a Pan, como recoge W. K. Pritchett (1979, p. 45) y, sin embargo, Eneas sólo

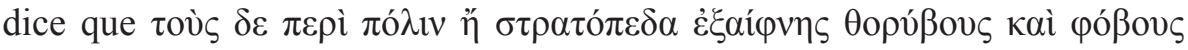

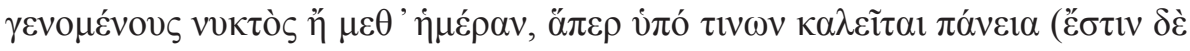

\footnotetext{
${ }^{49} \mathrm{Plu} .$, Is. et Os. 14: "El espanto súbito se conoce y se denomina a partir de aquel día terrores pánicos...”.

${ }^{50}$ Paus. X 23.7.

${ }^{51}$ Orph., H. 8.

${ }^{52}$ Longus II 20, 27.

${ }^{53}$ La misma teoría sostienen R. Lonis 1979, p. 182 o W. H. Pritchett 1979, p. 5. Por su parte, P. Borgeaud 1988, p. 100, considera que el éxito de Pan como dios militar le llegó cuando Fobos, el hijo de Ares, perdió prestigio. Entonces fue sustituido por el cabrero.
} 


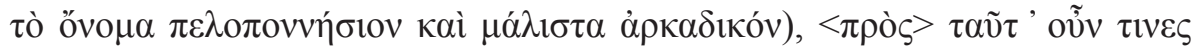

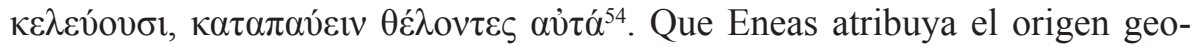
gráfico del término a Arcadia no implica que esté afirmando que el pánico es producido por Pan, aunque Pan sea el dios más importante de Arcadia. El propio término pánico, que a primera vista procedería del teónimo, vendría según R. Lonis (1979, p. 182) de paneion, nombre de la señal ígnea que anunciaría el miedo desatado entre las tropas.

La única referencia realmente clara a Pan como un dios guerrero la vemos en Dafnis y $C_{l o e^{55}}$ y parece más una necesidad del juego poético y de la trama novelesca que una atribución razonada. Por lo demás, cuando el dios hace acto de presencia en la contienda siempre es desde lejos, como mensajero del pánico, pero no como soldado activo ${ }^{56}$. Significativo también es que sólo se tenga noticia de dos epifanías de Pan en una batalla: Maratón ${ }^{57}$ y una muy dudosa en la batalla de Antígono Gónatas contra los gálatas ${ }^{58}$ (W. K. Pritchett 1979, p. 226; R. Lonis 1979, p. 182; M. Launey 1944, pp. 217-234). Por tanto, ¿por qué se asociaron, hasta prácticamente formar uno solo, Pan y el pánico, cuando también otros dioses practicaban con frecuencia la teolepsia? Creo que hay varias razoanes que pueden explicarlo.

En primer lugar, Pan es un dios de los pastores, pero también de los cazadores $^{59}$. A menudo las fuentes antiguas comparan la cinegética con el ejercicio bélico ${ }^{60}$, ya que ambas actividades poseen un principio común (abatir al enemigo) y ambas exigen sacrificios similares para expiar la mancha de la

${ }^{54}$ Aen. Tact. 27.1: "En cuanto a los alborotos y a los tumultos que se producen súbitamente en la ciudad, de día o de noche, y que algunos denominan pánicos (es un término peloponesio y especialmente arcadio), contra estos fenómenos hacen algunos las siguientes recomendaciones para hacerlos cesar (...)".

${ }_{55}^{5}$ Longus II 24-26.

${ }^{56}$ E., Rh. 35-39; Sil.Ital. XIII 300-302; D.C. I 6; Plu., Is. et Os. 14 y Pomp. 68 (no hace alusión alguna que conecte al pánico con una divinidad específica); Paus. X 23.6.

${ }^{57}$ Hdt., VI 105-106; Paus. I 28.4 y VIII 54.6. También se ha hablado de una epifanía en Platea siguiendo el texto de Plutarco (Arist. 11), pero Plutarco no menciona una teofanía, tan solo afirma que el oráculo de Delfos había predicho que los atenienses ganarían la batalla si honraban a Zeus, Hera Citeronia, Pan y las Ninfas Esfragítidas y sacrificaban a algunos héroes concretos. Aún menos verosímil es la aparición de Pan en la batalla de Salamina. La referencia para sostener esta información es un pasaje de Los Persas de Esquilo (v. 448-450), pero en él no se menciona la intervención militar de Pan, sino la existencia, frente a Salamina, de una isla pequeña y carente de puerto protegida por Pan, amante de la danza.

${ }^{58}$ Paus. X 23.7; Plin., NH XXXV 36, 63.

${ }^{59}$ Ver notas 12,14 y 15.

${ }^{60}$ A., A. 694-695. 
muerte sin la que no se generaría la vida (W. Burkert 1983). Así que no debe resultarnos extraño que sea precisamente una divinidad cazadora la que se alce con el título de dios del pánico.

En segundo lugar, Pan mantiene una doble relación con la guerra, sin ser él mismo guerrero. Por un lado, es una deidad de los límites, característica de los santuarios extraurbanos ${ }^{61}$. Dichos santuarios tienen un papel básico en la conformación de las fronteras de una comunidad y, por lo tanto, en la guerra. Un caso que demuestra bien este punto es el del santuario de la Ártemis Limnátide, compartida por mesenios y espartanos. Las versiones de unos y de otros sobre el significado, función y fundación del santuario son muy dispares y reflejan los diferentes planteamientos políticos. Para los lacedemonios, fueron los mesenios los que comenzaron la lucha que llevó a la construcción del santuario de frontera: violaron a sus muchachas, que se suicidarían después por vergüenza, y asesinaron a quien trató de impedirlo, el rey Téleclo, descendiente del mítico rey Agis ${ }^{62}$. Los mesenios, en cambio, cuentan que fueron los espartanos quienes pertrecharon un complot contra sus aristoi, por envidia de su grandeza. Téleclo disfrazó a los efebos espartanos con ropas femeninas y los lanzó contra los mesenios. Cuando estos se dieron cuenta de quiénes los agredían se defendieron, dando muerte a los efebos y a su instigador ${ }^{63}$. El ritual de la Ártemis Limnátide, una recreación simbólica del enfrentamiento mítico, estaba dirigido a los efebos, pues ellos (tanto las muchachas violadas como los jóvenes asesinados) fueron los primeros damnificados de la mítica contienda y por ello tenían lugar ceremonias de travestismo y de muerte simbólica que representaban el paso de la efebía al estadio adulto de los jóvenes de ambos sexos (F. de Polignac 1984, p. 58). Situado en los límites de la chora, el santuario extraurbano configura territorio y limita físicamente el espacio que pertenece a la polis; se trata de

\footnotetext{
${ }^{61}$ Pan se encuentra presente en varios santuarios extraurbanos arcadios. En el Ménalo había dos: uno en el camino que unía el macizo montañoso con Megalópolis (Paus. VIII 36.7) y otro al lado contrario del Ménalo, en un bosquecillo (Paus. VIII 37.11). A unos kilómetros de Tegea, en el camino hacia Tirea, cruzando el río Gárate, había otro santuario de Pan con un bosquecillo sagrado de encinas (Paus. VIII 54.4), así como un altar situado en el camino de Tegea a Laconia (Paus. VIII 53.11). En el recinto sacro del Monte Liceo se tiene noticia de dos santuarios a Pan (Paus. VIII 38.5, no localizado, y Berecla), en el que recibía culto junto al Zeus Lykaios. También en las montañas Nomias Pausanias (VIII 38.11) habla de un santuario a Pan, aunque su localización se desconoce. En el templo de Apolo en Basas (Figalia) aparece con la advocación de Pan Bassitas (A., Fr. 98 y Crinágoras en AP VI 253) y de Pan Sinois (IG V 2.429; Paus. VIII 30.3).

${ }^{62}$ Paus. IV 4.2.

${ }^{63}$ Paus. IV 4.3.
} 
una expresión de su existencia, de la constatación de un poder que le permite no sólo organizarse como comunidad social sino también controlar el entorno (F. de Polignac 1984, p. 45 y 1994, p. 13). Su presencia y los dioses que en él se honran otorgan seguridad y crean comunidad pues es el recordatorio perenne de la victoria de la comunidad, ayudada por sus dioses, frente a todos los enemigos a los que se enfrenta diariamente (M. C. Cardete 2005, pp. 83-87).

Uno de los santuarios extraurbanos de Pan en los que se percibe la función del dios como constructor de identidad, como garante de la unidad de la comunidad alrededor de determinados valores y frente a sus enemigos, es el de Berecla, situado en uno de los contrafuertes meridionales del Liceo, cerca de las fuentes del río Neda. Los restos arquitectónicos de este santuario, de vida bastante corta (ss. VI-IV a. C.), son escasos, en parte porque fueron reutilizados para la construcción de una capilla ortodoxa todavía en pie (M. Jost 1985 , p. 187) ${ }^{64}$. Tampoco aparece como un referente en las fuentes $\mathrm{y}$, sin embargo, su importancia histórica viene marcada por una serie de exvotos de gran calidad procedentes de un taller local y datables entre el s. VI y el V a. C encontrados detrás de un aterrazamiento en el que también había restos de cenizas y huesos animales procedentes de sacrificios.

Los exvotos más destacados son un conjunto de estatuillas masculinas de bronce datadas entre finales del s. VII y el s. $\mathrm{V}^{65}$. Son los primeros bronces de lo que Lamb (1925-1926, pp. 134-135) calificó del "typical Arcadian style", caracterizado por unas proporciones determinadas (las cabezas son demasiado largas para el cuerpo, que tiende a ser corto) y un tema recurrente: figuras de pastores y/o cazadores con ocasionales incursiones en otras áreas. Concretamente los bronces de Berecla pueden subdividirse en dos categorías. La primera la forma un grupo de hombres barbados vestidos con capas cortas o totalmente desnudos. Todos lucen el pilos y algunos portan regalos para el dios (terneros, corderos...). Dos de estas estatuillas llevan inscrito el nombre de Pan y el de sus oferentes, Fauleas y Eneas res-

\footnotetext{
${ }^{64} \mathrm{Al}$ oeste de la capilla se encuentran restos de un muro de piedras groseramente trabajadas, así como de otro edificio, quizás un templo, del que se mencionaban, a principios del siglo pasado, algunas columnas jónicas y dóricas en mármol, restos de bloques de calcárea y un par de inscripciones ( $I G \mathrm{~V} 2.556$ e $I G \mathrm{~V} 2.557)$ con el nombre de Pan (K. Kourouniotis 1902). Cien metros al norte se hallaron vestigios de dos cisternas.

${ }^{65}$ Aparte de estas estatuillas también se encontraron terracotas de los siglos VI-V que representan a Silenos o Panes y a algunos pastores, una estatuilla femenina, algunos espejos miniaturizados y una lámpara de bronce con empuñadura en forma de tritón (M. Jost 1985, p. 187; K. Kourouniotis 1902; U. Hübinger 1992, pp. 198 y 202).
} 
pectivamente (L. H. Jeffery 1998, p. 210) ${ }^{66}$. La segunda está compuesta de hombres vestidos de forma similar pero lampiños, lo que parece indicar que son más jóvenes. Algunos se presentan en actitud oferente, transportando un gallo, o corderos o incluso un recipiente con fruta, mientras que otros lucen posturas marciales.

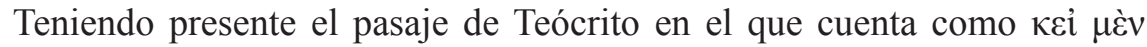

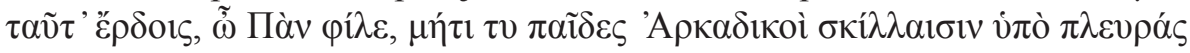

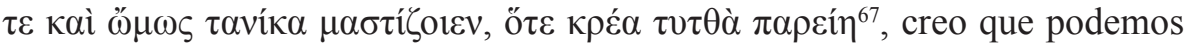
concluir que debió existir un rito de paso comunitario que se refleja en la diferencia de edad que representan estas figurillas. Aunque en Grecia no se conocen agones exclusivamente dedicados a la caza, no podemos obviar que los períodos de iniciación en los bosques solían incluir actividades cinegéticas y, dado que la caza era una actividad importante como representación social y como actividad económica menor, no es extraño que los jóvenes que se preparaban para adquirir responsabilidades adultas tuvieran que demostrar su pericia en este terreno, al igual que en otros (A. Brelich 1981, p. 175; P. Borgeaud 1979, p. 109). Además, también en Esparta los rituales de caza tenían presencia en las ceremonias iniciáticas, como ocurría con el llamado

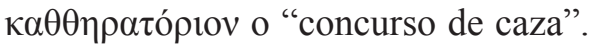

Por lo tanto, considero que las estatuas lampiñas representarían a los jóvenes que, por primera vez, se encaraban al dios que presidiría desde entonces una de las actividades más características de su nueva condición adulta, mientras que las barbadas harían lo propio con los adultos de la comunidad, a los que pronto se añadirían nuevos miembros. Así, sería Pan quien presidiría la entrada de los jóvenes en la esfera sacra de los adultos

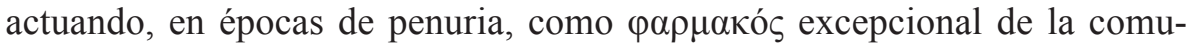
nidad, en una mezcla de los dominios iniciático y expiatorio ${ }^{68}$ (P. Borgeaud 1979, pp. 108-112).

${ }^{66}$ L. H. Jeffery 1998, p. 210, localiza estos exvotos en Melpea, aunque Hübinger cree que probablemente procedan de Berecla. Sobre la localización incierta de Melpea y las montañas Nomias, ver P. B. Broucke 1993.

${ }^{67}$ En el escolio al pasaje (Theoc., VII 106-114) se dice: "Cuando los arcadios salen de caza y tienen suerte veneran a Pan, pero, en caso contrario, lo maltratan con escilas ya que, siendo como es una deidad agreste, se le considera patrón de los cazadores. Munacio cuenta que en Arcadia se celebra una fiesta en la que los zagales golpean a Pan tirándole escilas".

${ }^{68} \mathrm{La}$ combinación de ambas esferas también aparece en la historia de la joven Polícrite de Naxos quien, abandonada por su comunidad, acaba siendo quien la salve de la invasión de los milesios (Parth. 9; Polyaen. VIII 36; Plu., Mul. Virt. 17 y Bonnechere 1994, pp. 305-306). 
Aparte del dominio iniciático, relacionado, como hemos visto, con la defensa del territorio y la conciencia de comunidad definida, Pan es arcadio y sus compatriotas son los mercenarios por excelencia del mundo griego desde las Guerras Médicas, si no antes (H. W. Parke 1970, p. 16) ${ }^{69}$. Los mercenarios arcadios cobraron fama en toda Grecia ${ }^{70}$ y cuando Licomedes se hizo cargo de la dirección de la Liga Arcadia arengó a sus tropas recordándoles que siempre que los griegos habían necesitado tropas habían recurrido a los mejores, es decir, a ellos ${ }^{71}$. Fue a partir del s. V a. C., tras las Guerras Médicas y la Guerra del Peloponeso, cuando adquirieron mayor importancia y es precisamente a partir de esta fecha cuando vemos a Pan asociado al pánico. Parece lógico que el dios más característicamente arcadio se convirtiera en un símbolo para sus compatriotas soldados y que, por tanto, pasara a ocupar un lugar de honor en la parafernalia militar. No había muchos más candidatos y, desde luego, ninguno tan bien dispuesto: Zeus (incluso bajo la advocación de Lykaios) era el dios griego por antonomasia y, por lo tanto, resultaba cuando menos problemático emplearlo como comodín en una batalla, ora ayudando a los unos ora a los otros. Lo mismo puede decirse de Hermes, Poseidón o Ártemis, fuertemente unidos al territorio arcadio pero también al resto de Grecia. Pan era una buena opción, un instrumento que atenienses y arcadios supieron utilizar con maestría en sus relaciones político-militares ${ }^{72}$.

La figura de Pan sigue muy presente en nuestra cultura. Entronizado durante el período helenístico, por la gracia de su nombre y de una falsa

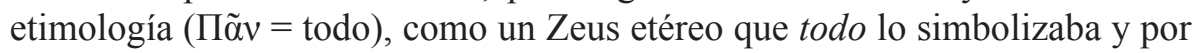

${ }^{69}$ Para una visión del mercenariado arcaico entendido como trasvase de tropas entre aristocracias y no como soldados a sueldo ver Bettalli 1995, Cardete 2003 y Cardete 2005, pp. 105-109.

${ }^{70}$ Para conocer la importancia de los mercenarios arcadios en Grecia v. Parke 1970. Tucídides menciona también su importancia en varios pasajes: I 114.4, II 70.3 y 74.3, III 34, IV 80.5, VII 57, VIII 3.28 y 107... También Hdt. VIII 26.

71 X., $H G$ VII 1.25 .

72 Sobre cómo Atenas construyó el mito del encuentro entre Pan y Filípides en el Partenio como un modo de afianzar las relaciones políticas con Tegea, enemiga de Esparta, en un momento en el que Atenas, victoriosa en las Guerras Médicas, comenzaba a forjar su poder, v. Cardete 2004. 
lo que todo existía, su música pastoril se convirtió en la música de las esferas de la que hablara Pitágoras y el baile ritual de un dios campestre en la ordenación cósmica de un mundo que demandaba orden tan desesperadamente como para obtenerlo de un dios de los límites y el caos. El Pan helenístico, neoplatonizado y espiritualizado al extremo, trascendió las fronteras temporales del mundo que lo creó para instalarse con todos los honores entre los misterios de la filosofía y el pensamiento moderno (J. Boardman 1997). Los alquimistas del Renacimiento lo hicieron partícipe de las conjeturas cabalísticas a las que eran tan aficionados y los pensadores cristianos lo elevaron a la condición de Cristo martirizado o de Diablo encarnado utilizando el pasaje de Plutarco que relata la muerte del Gran $\operatorname{Pan}^{73}$. Incluso hoy podemos comprobar la fascinación que produce el dios cabra, pues su imagen, cargada de esoterismo y misterio por el paso de los siglos y las tradiciones a él atribuidas, se repite en libros de misterio, en cuentecillos góticos que lucen su nombre en la portada como reclamo publicitario o en obras como la del poeta ucraniano Jodorowsky, fundador de lo que él llama el "movimiento pánico", que pretende convertir lo trágico en poético como un homenaje al dios Pan y, de paso, reírse del mundo y sus habitantes. Incluso se puede decir que, en el imaginario popular, continúa poseyendo a seres humanos, desvalidos ante su fuerza, y propiciando vencedores y vencidos en las batallas, ya que el Demonio que ensalzó el cristianismo no es otro que una réplica del Pan caprino, con cuernos, rabo y barba de chivo.

BiBLIOGRAFÍA

Bettalli, M. 1995: I mercenari nel mondo greco I. Dalle origini alla fine del $V$ sec. a. C., Pisa.

Boardman, J. 1997: The Great God Pan: the survival of an image (Walter Neurath Memorial Lecture 1997), Londres.

Bonnechere, P. 1994: Le sacrifice humain en Grèce ancienne, Kernos suppl. 3, Lieja. Borgeaud, P. 1979: Recherches sur le dieu Pan, Ginebra.

${ }^{73}$ Plu., De defectu oraculorum 17. La identidad del Gran Pan, cuya muerte relata Plutarco en un ambiente de misterio exótico, ha sido muy debatida: desde considerarlo como uno de los nombres de Zan (una antigua forma de Zeus cornudo que fue suplantado por Pan -Orph., H. 11.13-) (A. B. Cook 1914, pp. 347-349) o como el dios egipcio Mendes (W. H. Roscher 1897-1909, pp. 1347-1406) hasta verlo como el símbolo del paganismo agonizante cuya muerte deja paso al triunfo del cristianismo (P. Borgeaud 1983, pp. 260-261). 
- 1983: «The death of the Great Pan: the problem of interpretation» $H R$ 22, pp. 254-283.

- 1988: The cult of Pan in Ancient Greece, Chicago.

Brelich, A. 1981: Paides et parthenoi, Roma.

Broucke, P. B. 1993: «To the right of Lykosoura: Pausanias and the topography of the Nomian mountains», AJA 97, p. 345.

Burkert, W. 1983: Homo Necans, Los Ángeles.

Cardete del Olmo, M. C. 2003: «Identidad y religión: el santuario de Apolo en Basas», Studia Historica, Historia Antigua, 21, pp. 47-74.

- 2004: «La construcción de un mito: el encuentro entre Pan y Filípides en el Partenio» en Hernández Guerra, L. y Alvar Ezquerra, J. (eds.), Actas del XXVII Congreso Internacional GIREA-ARYS IX, Jerarquías religiosas y control social en el mundo antiguo, Valladolid 7-9 Noviembre 2002, Valladolid, pp. 215-222.

- 2005: Paisajes mentales y religiosos: la frontera suroeste arcadia en épocas arcaica y clásica, Oxford.

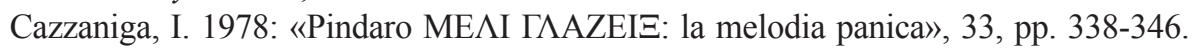

Chapman, J. 1997: «Place as timeless - the social construction of prehistoric landscapes in Eastern Hungary» en Nash, G. (ed.) Semiotics of landscape: archaeology of mind, Oxford, pp. 31-45.

Children, G. y Nash, G. 1997: «Establishing a discourse: the language of landscape» en Nash, G. (ed.), Semiotics of landscape: archaeology of mind, Oxford, 1-4.

Connor, W. R. 1988: «Seized by the Nymphs: Nympholepsy and simbolic expresion in Classical Greece», ClAnt 7, 155-189.

Cook, A. B. 1914-1925: Zeus. A study in Ancient Religion. Cambridge, 3 vols.

Dodds, E. R. 1960: Los griegos y lo irracional, Madrid.

Gallini, C. 1961: «La follia panica», Studi e materiali di storia delle religioni, 32, pp. 205-236.

Haldane, J. 1969: «Pindar and Pan», Phoenix, 21, pp. 18-31.

Hild, J. A. 1969: «Pan», DA, pp. 296-302.

Hübinger, U. 1992: «On Pan's iconography and the cult in the sanctuary of Pan on the slopes of Mount Lykaion» en Hägg, R. (ed.) The iconography of Greek cult in the Archaic and Classical periods. Proceedings of the First International Seminar on Ancient Greek cult, Atenas - Lieja, pp. 189-207.

Jeffery, L. H. 1998: The local scripts of Archaic Greece: a study of the origin of the Greek alphabet and its development from the eight to the fifth centuries $B$. $C$, Oxford.

Jost, M. 1985: Sanctuaries et cultes d'Arcadie, París.

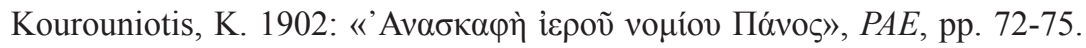

Lamb, W. 1925-1926: «Arcadian bronze statuettes», ABSA, 27 pp. 133-148.

Larson, J. 2000: Greek Nymphs. Myth, Cult and Lore, Nueva York.

EMERITA (EM) LXXVI 1, enero-junio 2008 pp. 67-85

ISSN 0013-6662 
Launey, M. 1944: «Études d'histoire hellénistique», REA 46, pp. 217-234.

Lonis, R. 1979, Guerre et religion en Grèce a l'époque classique, Besançon.

Mactoux, M. M. 1975: Pénélope: légende et mythe, París.

Meillier, C. 1975: «L'épiphanie du dieu Pan au livre II de Daphnis et Chloé», REG 88, pp. 121-132.

Parke, H. W. 1970: Greek mercenary soldiers. From the earliest times to the battle of Ipsus, Londres.

Polignac, F. de 1984: La naissance de la cité grecque, París.

- 1994: «Mediation, competition and sovereignty: the evolution of rural sanctuaries in Geometric Greece» en Alcock, S. and Osborne, R. (eds.), Placing the gods. Sanctuaries and sacred space in Ancient Greece, Oxford, pp. 3-18.

Pritchett, W. K. 1979: The Greek State at war. Part III: Religion, Londres.

Roscher, W. H. 1897-1909: Ausführliches Lexikon Der griechischen und römischen Mythologie, Leizpig.

Tilley, Ch. 1994: A phenomenology of landscapes. Places, paths and monuments, Oxford.

Fecha de recepción de la primera versión del artículo: 10/04/2007

Fecha de aceptación del artículo: 17/10/2007

Fecha de recepción de la versión definitiva del artículo: 14/06/2008 